\title{
TWO ISSUES DEDICATED TO PROFESSOR V. V. ZHIKOV ON THE OCCASION OF HIS 70 ${ }^{\mathrm{TH}}$ BIRTHDAY
}

Two issues of Journal of Mathematical Sciences, N. Y. (176, No. 6 and 177, No. 1, August 2011) are dedicated to the 70th birthday of the outstanding Russian mathematician Professor V. V. Zhikov. More than 40 authors present their recent research results in various areas close to the scientific interests of V. V. Zhikov. Some of the authors were invited speakers at the International Conference on the occasion of Zhikov's 70th birthday "Multiscale Methods and Qualitative Properties for Differential Operators" held in Naples, Italy on May 6-7, 2011. Kind consultations of Professors Yu. Alkhutov, G. Panasenko, and A. Piatnitski were very helpful for gathering and preparing these issues.

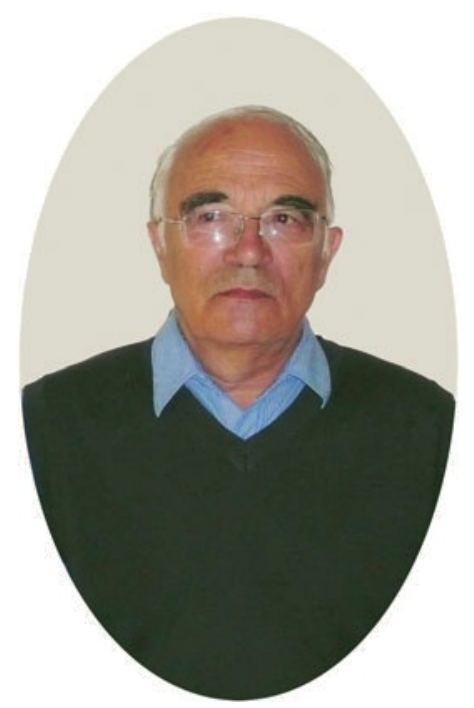

Vasilii Zhikov was born on August 14, 1940. He graduated from the Lomonosov Moscow State University in 1963. He received his Ph.D. in 1966 and D.Sci. degree in 1975. Since 1966 Vasilii Vasil'evich Zhikov lives and works in Vladimir - the ancient Russian city situated in $180 \mathrm{~km}$ from Moscow. At present, V. V. Zhikov is a Full Professor of the Vladimir State University.

Professor V. V. Zhikov is internationally recognized for his influential scientific works covering numerous important topics in the theory of PDEs and functional analysis: homogenization of differential operators and variational functionals, asymptotic analysis, multiscale methods and applications to boundary value problems in perforated domains occupied by composite materials, almost periodic functions and solutions of differential equations, qualitative properties for differential operators, stabilization of solutions to parabolic equations, spectral problems in double porocity models, variational problems for Lagrangians of nonstandard growth, homogenization on periodic networks, junctions, and more general multi-dimensional structures, problems of the theory of elasticity and corresponding weighted Sobolev spaces in singular structures, degenerate second order differential operators, and so on.

V. V. Zhikov is an author of several monographs and more than 150 scientific papers. In particular, his papers have been published in the following issues of Journal of Mathematical Sciences, N.Y.: 85, No. 6 (1997); 114, No. 1 (2003); 120, No. 3 (2004); 123, No. 5 (2004); 129, No. 1 (2005); 132, No. 3 (2006); 135, No. 1 (2006); 144, No. 1 (2007); and 173, No. 5 (2011).

Translated from Problems in Mathematical Analysis 58, June 2011, p. 3.

1072-3374/11/1766-0709 (C) 2011 Springer Science+Business Media, Inc. 